\title{
Retrieval of a Dislocated Stent Using a Grasping Forceps and a Steerable Sheath in a Fontan Patient
}

\author{
Torben Kehl $^{1}$ Götz Müller ${ }^{1} \quad$ Carsten Rickers $^{2} \quad$ Rainer Kozlik-Feldmann ${ }^{1}$ \\ ${ }^{1}$ Children's Heart Clinic, University Medical Center Hamburg- \\ Eppendorf, Hamburg, Hamburg, Germany \\ 2 Adult with Congenital Heart Disease Section, University Medical \\ Center Hamburg-Eppendorf, Hamburg, Hamburg, Germany \\ Address for correspondence Torben Kehl, MD, Children's Heart \\ Clinic, University Heart and Vascular Center Hamburg, University \\ Medical Center Hamburg-Eppendorf, Hamburg, Germany \\ (e-mail: t.kehl@uke.de).
}

Thorac Cardiovasc Surg Rep 2022;11:e4-e6.

\author{
Abstract \\ Keywords \\ - cardiac \\ catheterization/ \\ intervention \\ - congenital heart \\ disease \\ - pulmonary arteries \\ - complication \\ management \\ - stent retrieval
}

In Fontan patients, any pulmonary stenosis may impede free passive inflow into the pulmonary circuit and elevate central venous pressure. When stenting such pulmonary stenosis, dislocation of a stent is a feared complication. Here, we report on a successful retrieval of a dislocated Cook Formula stent into the peripheral left pulmonary artery in a Fontan patient with protein-losing enteropathy using a steerable sheath and a grasping forceps. Furthermore, a successful stent implantation for treating the stenosis was possible. Subsequently, we simulated the retraction technique ex vivo. To manage stent dislocation during complex pediatric catheter interventions, we can recommend the use of a steerable sheath guiding a grasping forceps. A dislocated stent can be grasped, completely longitudinally refolded, and safely retrieved.

\section{Introduction}

Stent dislocation during or after implantation is a dreaded complication of pediatric interventional cardiology. ${ }^{1}$ An embolism of a dislocated stent into peripheral, poorly accessible vessels can complicate stent retrieval. An unfolded stent that cannot be refolded sufficiently at the sheath carries a relevant risk of vascular injury in the event of retraction.

In patients with a Fontan circulation, especially in a failing situation with existing protein-losing syndrome, any loss of flow energy in the pulmonary circulation caused by stenosis of the pulmonary arteries is harmful and must be treated consequently. ${ }^{2-4}$ In case of unsuccessful treatment results using balloon dilatation, a stent implantation may be indicated to improve the pulmonary flow. 5,6

\section{Case Presentation}

Here, we report an 8-year-old patient with double inlet left ventricle in Fontan circulation who suffered from a failing Fontan situation with protein-losing enteropathy. Cardiac magnetic resonance imaging showed evidence of left pulmonary artery (LPA) stenosis; therefore, indication for diagnostic cardiac catheterization was made. We detected a relevant $50 \%$ stenosis of the LPA proximal to the pulmonary artery (PA) bifurcation ( - Fig. 1A; diameter of LPA stenosis $4.8 \mathrm{~mm}$, LPA distal $9.5 \mathrm{~mm}$ ) with a pressure gradient of $5 \mathrm{~mm}$ $\mathrm{Hg}$ (systolic gradient between PA and distal LPA). After unsuccessful multiple balloon dilatations with NuMed Tyshak Mini $8 \mathrm{~mm}$ (pfm medical, Cologne, Germany) and Ultraverse $03510 \times 20 \mathrm{~mm}$ (Bard Peripheral Vascular Inc., Arizona, United States), the decision to implant a stent was received

May 4, 2021

accepted after revision

June 29, 2021
DOI https://doi.org/

10.1055/s-0041-1736207.

ISSN 2194-7635. (c) 2022. The Author(s).

This is an open access article published by Thieme under the terms of the Creative Commons Attribution-NonDerivative-NonCommercial-License, permitting copying and reproduction so long as the original work is given appropriate credit. Contents may not be used for commercial purposes, or adapted, remixed, transformed or built upon. (https://creativecommons.org/ licenses/by-nc-nd/4.0/) Georg Thieme Verlag KG, Rüdigerstraße 14, 70469 Stuttgart, Germany 

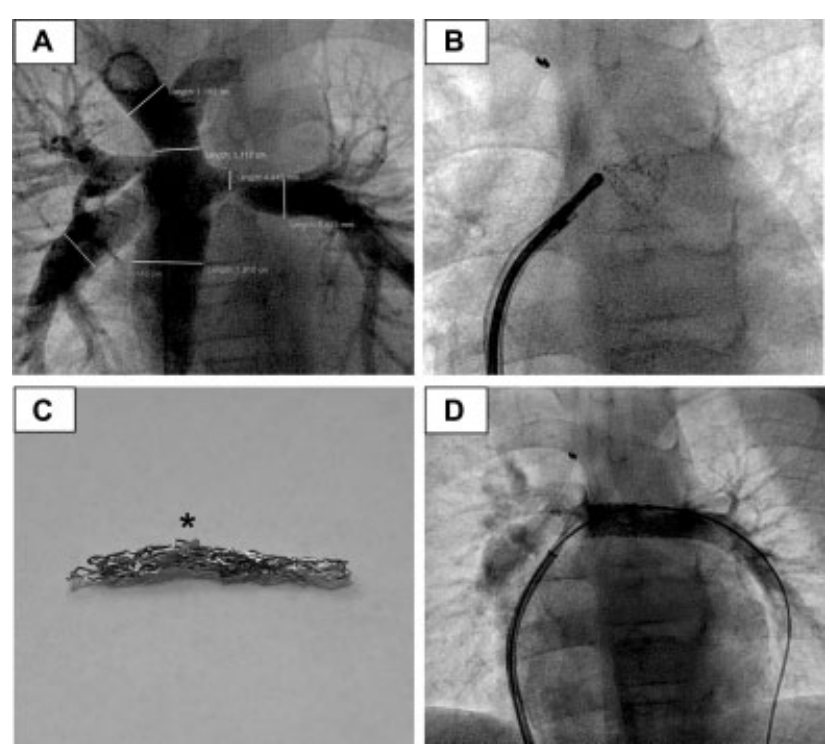

Fig. 1 (A) Preinterventional angiography with LPA stenosis (reduced vessel diameter $4.8 \mathrm{~mm}$, LPA distal $9.5 \mathrm{~mm}$ ). (B) Fluoroscopic control of the retrieval of the refolded Cook Eq. 535 stent. (C) Explanted refolded stent with signs for minimal intima lesion (asterisk). (D) Final angiography with improved vessel diameter and no indication of vascular complications. LPA, left pulmonary artery.

made. The implantation of an $8 \times 12 \mathrm{~mm}$ Cook Eq. 535 stent (Cook Medical, Bloomington, Indiana, United States) resulted in distal slippage of the stent during implantation ( - Video 1). Retraction of the stent via balloon catheter into the stenosis area was unsuccessful. The stent was then deployed to the periphery below PA by means of further retraction maneuvers. There was the indication for salvaging the stent with a Maslanka grasping forceps (Maslanka, Tutlingen, Germany). It was not possible to pass the LPA stenosis with a Cook Check-Flo 6F sheath (Cook Medical, Bloomington, Indiana, United States), a Terumo 6F long sheath (Terumo, Tokyo, Japan), or a Terumo 7F Destination sheath. Furthermore, it was not possible to navigate the forceps sufficiently through the sheath catching the stent. After changing to a steerable Oscor Destino Twist 6.5F sheath (Oscor, Palm Harbour, Florida, United States), the Maslanka grasping forceps could be navigated sufficiently. This allowed the proximal stent end to be grasped. A retraction into the stenosis area followed, here the stent could be refolded longitudinally under intermittent traction directly at the distal end of the 6.5F sheath and pulled into ( - Fig. 1B and - Video 2). The stent could be fully explanted over the inserted sheath. Despite signs of questionable intima lesion on the explanted stent (-Fig. 1C), no evidence of relevant vascular injury could be seen in different control angiographies. Furthermore, a new $8 \times 12 \mathrm{~mm}$ Cook Eq. 535 stent could be correctly implanted in the LPA stenosis area via a Terumo $6 \mathrm{~F}$ long sheath. The final angiography showed an improvement in the vessel diameter and no indication of vascular complications ( - Fig. 1D and - Video 3 ).

\section{Video 1}

The unsuccessful stent implantation with distal slippage of the stent during implantation. Online content including video sequences viewable at: https://www.thieme-connect.com/products/ ejournals/html/10.1055/s-0041-1736207.

\section{Video 2}

The complete retrieval of the refolded stent into the steerable 6.5F sheath. Online content including video sequences viewable at: https://www.thieme-connect. com/products/ejournals/html/10.1055/s-00411736207.

\section{Video 3}

The final angiography after successful stent implantation with improved diameter of the left pulmonary artery and no signs for pulmonary vessel injury after stent retrieval and new stent implantation. Online content including video sequences viewable at: https://www.thieme-connect.com/products/ ejournals/html/10.1055/s-0041-1736207.

\section{Discussion}

Stent dislocation is a rare but dreaded complication in interventional treatment of complex congenital heart disease. ${ }^{1}$ Systematic scientific studies on this complication are lacking. In the case presented here, successful retrieval of a dislocated, already deployed Eq. 535 stent was achieved without any relevant vascular injury. To further investigate the possibilities of such an interventional stent retrieval technique, we subsequently simulated the procedure ex vivo (-Fig. 2A, B and -Video 4). Here, we were able to reproduce complete refolding of a deployed Eq. 535 stent. By repeatedly gently advancing and retracting the forceps at the distal end of the sheath and pulling into the sheath, the stent could be completely longitudinally refolded ( - Fig. 2C). Due to the force exerted on the distal end of the sheath by this procedure, leading to deformation ( - Fig. 2D), we recommend using a stable sheath, such as Cook Flexor Check-Flo or Oscor Destino Twist sheath, for stent retrieval with the presented technique. Injury to the intima remains a possible dangerous complication even with this retrieval technique, especially during the final pull into the sheath end. Such an intimal injury should be avoided by careful retraction maneuvers. 

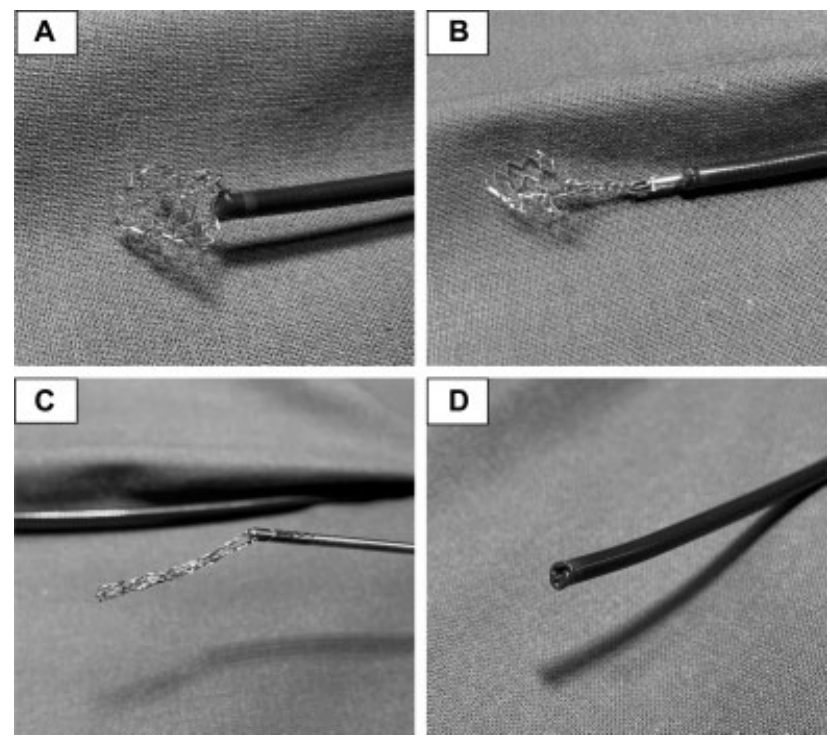

Fig. 2 (A, B) Grasping of the deployed stent with grasping forceps, pulling of the grasping forceps at the distal end of the sheath, and the associated refolding of the stent (see also - Video 4). (C) The fully longitudinally refolded stent. (D) The distal end of the sheath mildly destructed by stent retraction.

\section{Video 4}

Redrawn simulated stent retrieval: a deployed Cook Eq. 535 stent is grasped with a Maslanka grasping forceps and carefully folded back fully longitudinally with forward and retraction maneuvers under tension and pulled into a Cook Flexor Check-Flo sheath. The refolded stent and the mildly destructed distal end of the sheath are then shown (see also - Fig. 2) Online content including video sequences viewable at: https:// www.thieme-connect.com/products/ejournals/html/ 10.1055/s-0041-1736207.

\section{Conclusion}

Management of complication during complex interventions in patients with congenital heart defects is of crucial importance. In case of dreaded stent embolism, we can recommend the use of a steerable sheath to improve forceps guiding for grasping a dislocated stent. In our experience, by using a guided forceps, a Cook Eq. 535 stents can be grasped, completely longitudinally refolded at the distal sheath end, and retrieved through a steerable sheath.

\section{Ethics Approval}

An ethics vote was not obtained.

\section{Consent to Participate}

There is written consent to participate.

\section{Consent for Publication}

There is a written consent for anonymous publication of the patient's data signed by the parents acting as legal guardian.

\section{Availability of Data and Materials}

The entire data are available anonymized.

\section{Code Availability}

Not necessary.

\section{Authors' contribution}

All authors performed the published catheter intervention, performed the described simulated stent retrieval procedure ex vivo, edited all figures and videos, wrote the manuscript significantly, and Assisted in planning the publication and writing the manuscript. All authors read and approved the final manuscript.

\section{Funding}

None.

\section{Conflict of Interest}

None declared.

\section{References}

1 Holzer RJ, Gauvreau K, Kreutzer J, et al. Balloon angioplasty and stenting of branch pulmonary arteries: adverse events and procedural characteristics: results of a multi-institutional registry. Circ Cardiovasc Interv 2011;4(03):287-296

2 Stern HJ. Fontan “Ten Commandments" revisited and revised. Pediatr Cardiol 2010;31(08):1131-1134

3 Gewillig M, Brown SC. The Fontan circulation after 45 years: update in physiology. Heart 2016;102(14):1081-1086

4 Alsaied T, Sleeper LA, Masci M, et al. Maldistribution of pulmonary blood flow in patients after the Fontan operation is associated with worse exercise capacity. J Cardiovasc Magn Reson 2018; 20(01):85

5 Noonan P, Kudumula V, Anderson B, et al. Stenting of the left pulmonary artery after palliation of hypoplastic left heart syndrome. Catheter Cardiovasc Interv 2016;88(02):225-232

6 Hauck A, Porta N, Lestrud S, Berger S. The pulmonary circulation in the single ventricle patient. Children (Basel) 2017;4 (08):71 